\title{
La Réception de Racine à l'âge classique: de la scène au monument. Études présentées par Nicholas Cronk et Alain Viala
}

\section{Regina Bochenek Franczakowa}

\section{(2) OpenEdition \\ Journals}

Edizione digitale

URL: http://journals.openedition.org/studifrancesi/27572

ISSN: 2427-5856

\section{Editore}

Rosenberg \& Sellier

\section{Edizione cartacea}

Data di pubblicazione: 31 décembre 2006

Paginazione: 600

ISSN: 0039-2944

Notizia bibliografica digitale

Regina Bochenek Franczakowa, "La Réception de Racine à l'âge classique: de la scène au monument. Études présentées par Nicholas Cronk et Alain Viala », Studi Francesi [Online], 150 (L | III) | 2006, online dal 30 novembre 2015, consultato il 08 novembre 2020. URL : http://journals.openedition.org/ studifrancesi/27572

Questo documento è stato generato automaticamente il 8 novembre 2020. 


\title{
La Réception de Racine à l'âge classique: de la scène au monument. Études présentées par Nicholas Cronk et Alain Viala
}

\author{
Regina Bochenek Franczakowa
}

\section{NOTIZIA}

La Réception de Racine à l'âge classique: de la scène au monument. Études présentées par Nicholas CRONK et Alain VIALA, Oxford, Voltaire Foundation, 2005 («SVEC 2005: 08»), pp. 245.

1 La «réception» permet mieux que tout autre problème de mesurer la présence et la fortune d'une grande œuvre littéraire. La notion même de réception se trouve ici élargie afin d'embrasser aussi les divers aspects de l'art dramatique chez Racine: lecture, commentaire, mais encore, représentation, enseignement et édition. L'ouvrage se compose de quatre parties. La première («Les espaces de la réception de Racine à l'âge classique») présente comment Racine devint un auteur «classique» de la littérature française moderne dès la fin du XVII ${ }^{e}$ siècle. Junga SHIN (La construction d'un 'Racine classique' au dix-huitième siècle: ambivalences des images, pp. 5-19) présente les trois images de Racine qui se sont formées au XVIII ${ }^{\mathrm{e}}$ siècle: peintre de la passion, auteur de tragédies et poète chrétien. «Racine classique» est loin d'être univoque. Michèle RosSELlini (Aux origines du classique scolaire: la lecture poétique de Racine par l'abbé Batteux, pp. 20-34) saisit le moment où les auteurs français furent introduits dans l'enseignement: le manuel de l'abbé Batteux illustre la manipulation exercée sur les tragédies de Racine, qui est à la base de la consécration du dramaturge en poète lyrique. Fanny MALTERRE et Alain VIALA (Racine à la Comédie-Française: tendances majeures, pp. 35-38) répertorient les représentations des tragédies raciniennes de 1680 à 1790; ils 
y distinguent une ligne générale d'évolution et effectuent un classement des pièces selon leur popularité. Dinah RIBARD (Racine sans théâtre: le travail biographique dans les «Mémoires sur la vie de Jean Racine», pp. 39-58) rappelle que la biographie de Racine, retracée par son fils Louis et l'abbé d'olivet, donna matière à des polémiques qui furent à la source de toute une tradition interprétative et éditoriale de l'œuvre racinienne. Claire Cazanave (Un livre monument: l'édition Didot de 1801 des «Euvres de Racine», pp. 59-67) présente l'édition de luxe dédiée par Didot au Premier Consul: l'éditeur se met en vedette, surajoutant à l'œuvre une signification de «l'idéologie de la monumentalité» (p. 67). La deuxième partie («Aspects de la réception critique») aborde la problématique dans son acception traditionnelle. Alain VIALA (Des conflits et des larmes, pp. 73-83) avance l'idée que la réception de Racine fut dès son vivant scénique et émotive, que c'est au XVIII ${ }^{e}$ siècle que son théâtre obtint le succès éditorial et lectoral; mais encore, que Racine avait joué sur cette double réception. Jonathan MALLINSON (Des rires et des pleurs: Racine, Molière et la réception de la tragédie, pp. 84-99) compare des scènes de Britannicus et de L'Avare pour démontrer que le tragique et le comique peuvent se trouver fort près l'un de l'autre. David MASKell (Poésie et grammaire chez Racine: «les Remarques» de l'abbé d'olivet, pp. 100-106) examine les remarques de l'abbé d'olivet sur le style racinien lequel suscita d'assez vives critiques chez ses contemporains. Edward NYE (Eighteenth-century views of Racinian «harmonie poétique», pp. 107-115) s'intéresse à «l'harmonie poétique» de Racine, surtout, à «l'harmonie imitative» (iconic versification) appréciée par Marmontel et Du Marsais. La troisième partie («Métamorphoses créatrices») élargit la problématique sur les autres écrivains. David Wiluiams (Voltaire et le tragique racinien, pp. 121-132) considère les diverses faces de la vénération vouée par Voltaire au théâtre de Racine, insistant sur les raisons de ses préférences. Nicholas CRONK («L'Iphigénie» de Saint-Foix et l'esthétique du tableau: réécrire Racine en 1769, pp. 133-144) fait une ample présentation (avec le texte en appendice) de la célèbre réécriture des dernières scènes d'Iphigénie par Saint-Foix; conformément à l'esthétique théâtrale de l'époque, le sacrifice de l'héroïne fut représenté en tableau. Russell GOULBOURNE (Remembering and dismembering Racine in the eighteenth century, pp. 145-169), examine les textes de La Harpe, Diderot, Fénelon et Du Cerceau afin de tracer l'origine du mythe de Racine au XVIII siècle, celui du poète à lire. La quatrième partie («De l'âge classique à la seconde modernité») étend la réception de Racine jusqu'aux temps modernes. François LAGARDE (La valeur et l'effet de nature: réceptions de Racine après la Révolution, pp. 175-189) réfléchit sur deux types de réception de Racine: la «réception idéologique» et la "réception mimétique». Kate E. TUNSTALL (Racine in 1769 and 1910, or Racine «à l'usage de ceux qui voient», pp. 190-205) juxtapose deux adaptations de Racine: celle d'Iphigénie faite par Saint-Foix et celle, filmique, d'Athalie: dans les deux cas, la transformation des paroles en spectacle, donne une version inattendue de Racine, située entre la tragédie, le drame et le mélodrame. Henry PHILLIPS (Racine: perspectives critiques et dramaturgiques, pp. 206-219) passe en revue et caractérise les diverses recherches sur l'œuvre racinienne, dans la perspective du Tricentenaire de 1999. Le volume est clos par l'article de Bruno BLANCKEMAN(Festival d'Avignon 1998: présence de Jean Racine, pp. 220-226) qui évoque les représentations des tragédies de Racine dans le programme "off" du Festival d'Avignon, présence qui, en définitive, s'est soldée par l'échec.

2 En guise de conclusion, il faudrait convenir avec A. Viala que «Racine est un bel exemple, avec une belle continuité historique jusqu'à nos jours, de réceptions 
différentes, contrastées, contradictoires et polémiques» (p. 81), phénomène que ce volume illustre par la richesse des aperçus, approches et perspectives nouvelles. 